"This is the peer reviewed version of the following article: A Million Turnover Molecular Anode for

Catalytic Water Oxidation, which has been published in final form at

http://onlinelibrary.wiley.com/doi/10.1002/anie.201609167/abstract

This article may be used for non-commercial purposes in accordance with Wiley Terms and Conditions for SelfArchiving."

\title{
A Million Turnover Molecular Anode for Catalytic Water Oxidation
}

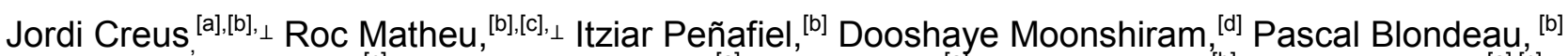 \\ Jordi Benet-Buchholz, ${ }^{[c]}$ Jordi García-Antón, ${ }^{[a]}$ Xavier Sala, ${ }^{\left[{ }^{[a], *}\right.}$ Cyril Godard, ${ }^{[b], *}$ Antoni Llobet, ${ }^{[a],[c], *}$
}

\begin{abstract}
Molecular Ru based water oxidation catalysts precursors of general formula $\left[\mathrm{Ru}(\mathrm{tda})\left(\mathrm{L}^{\mathrm{i}}\right)_{2}\right]\left(\mathrm{tda}^{2-}\right.$ is $\left[2,2^{\prime}: 6^{\prime}, 2^{\prime \prime}\right.$-terpyridine $]-6,6$ "dicarboxylato; $\mathrm{L}^{1}=4$-(pyren-1-yl)-N-(pyridin-4-ylmethyl)butanamide, 1b; $L^{2}=4-($ pyren-1-yl)pyridine ), 1c), have been prepared and thoroughly characterized. Both complexes contain a pyrene group allowing ready and efficiently anchoring via $\pi$ interactions on MultiWalled Carbon Nanotubes (MWCNT). These hybrid solid state materials are exceptionally stable molecular water oxidation anodes capable of carrying out more than a million Turnover Numbers (TNs) at $\mathrm{pH} 7$ with an $E_{\mathrm{app}}=1.45 \mathrm{~V}$ vs. NHE without any sign of degradation XAS spectroscopy analysis before, during and after catalysis together with electrochemical techniques allow to monitor and verify their unprecedented oxidative ruggedness.
\end{abstract}

Visible light induced water splitting to produce hydrogen fuel is one of the potential alternatives to fossil fuels. ${ }^{1}$ To achieve this goal, powerful and rugged Water Oxidation Catalysts (WOCs) that can be anchored onto solid-state devices to facilitate water splitting cell assembling and engineering are needed. ${ }^{2,3,45}$ In the molecular front, it is imperative to have water oxidation catalysts that can work under restricted translational mobility conditions, ${ }^{6}$ and whose O-O bond formation step occurs via a "Water Nucleophilic Attack" mechanism (WNA). ${ }^{7,8}$ Molecular WOCs whose low energy $\mathrm{O}-\mathrm{O}$ bond formation pathways in

[a] J. Creus, Dr. J. García-Antón, Dr. X Sala, Prof. A. Llobet Departament de Química, Universitat Autònoma de Barcelona Carrer dels Til.lers $s / n$,

08193 Bellaterra (Cerdanyola del Vallès) Barcelona, Spain. E-mail: xavier.sala@uab.cat

[b] J.Creus, R. Matheu, Dr. I. Peñafiel, Dr. P. Blondeau, Dr. C. Godard Departament de Química Física i Inorgànica, Universitat Rovira i Virgili

Carrer Marcel·lí Domingo s/n

43007 Tarragona, Spain

E-mail: cyril.godard@urv.cat

[c] R. Matheu, Dr. J. Benet-Bucholz, Prof. A. Llobet Institute of Chemical Research of Catalonia (ICIQ), Barcelona Institute of Science and Technology Avinguda Països Catalans 16

43007 Tarragona, Spain

E-mail: allobet@iciq.cat

[d] Dr. D. Moonshiram

Chemical Science and Engineering Division, Argonne National Laboratory

9700 S. Cass Avenue

Lemont IL 60439, U.S.A

Supporting information for this article is given via a link at the end of the document. homogeneous phase occur via an "Interaction of 2 M-O units" (I2M) might still be able to carry out the catalytic water oxidation reaction at the surface of an electrode, but will need to proceed through higher energy pathways that can lead to catalyst degradation. ${ }^{6}$ Further, given the intrinsic high energy demands for the water oxidation catalysis, it is essential that the anchoring groups that act as an interface between the catalysts and surface are oxidatively resistant.

Here on, we report new hybrid materials consisting of molecular WOCs anchored onto Multi-Walled Carbon Nanotubes (MWCNTs) via $\pi$-stacking interactions. ${ }^{9}$ The resulting materials are extremely stable and allow the anchoring of a large amount of catalyst giving Turnover Numbers (TNs) over a million without apparent deactivation.

In a recent publication, ${ }^{10}$ we have reported the synthesis of complex $\left\{R u^{\prime \prime}(\mathrm{tda})(\mathrm{py})_{2}\right\}, 1 \mathrm{1a}$, (for a drawing of $\mathrm{tda}^{2-}$ see Scheme 1 ) and have shown that in its high oxidation states (IV) acts as a precursor for the formation of $\left\{\mathrm{Ru}^{\mathrm{V}}(\mathrm{O})(\mathrm{tda})(\mathrm{py})_{2}\right\}^{+}$. The latter is the most powerful molecular water oxidation catalyst described to date achieving Turnover Frequencies (TOF) in the range of $50.000 \mathrm{~s}^{-1}$. In addition, we showed that the rate determining step for the water oxidation reaction is the $\mathrm{O}-\mathrm{O}$ bond formation, which in this case occurs via WNA, as evidenced by kinetics and further supported by DFT calculations.

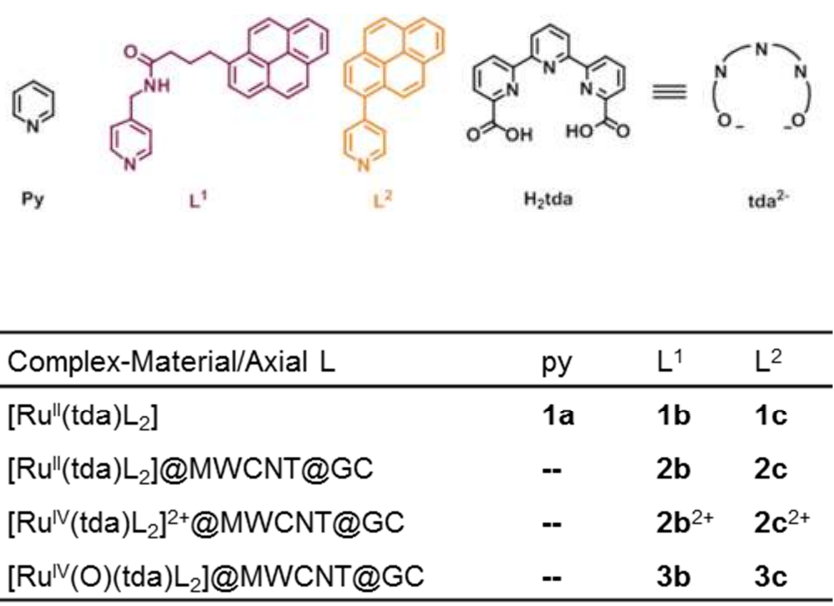

Scheme 1. Drawing of the ligands discussed in the present work (top) and complex labelling strategy (bottom). 
"This is the peer reviewed version of the following article: A Million Turnover Molecular Anode for

Catalytic Water Oxidation, which has been published in final form at http://onlinelibrary.wiley.com/doi/10.1002/anie.201609167/abstract

This article may be used for non-commercial purposes in accordance with Wiley Terms and Conditions for SelfArchiving."

Given the remarkable performance of $\left\{\operatorname{Ru}^{\mathrm{V}}(\mathrm{O})(\mathrm{tda})(\mathrm{py})_{2}\right\}^{+}$, we proceeded to anchor it on conductive solid supports with the aim of generating a powerful hybrid anode for the electrocatalytic oxidation of water to dioxygen, that could be potentially incorporated in water splitting devices. For this purpose, we used MWCNTs as support, given their high stability, conductivity and large electrochemically active surface area. ${ }^{9,11}$ Further, MWCNTs were selected because of their inertness as compared to oxides that can potentially block labile Ru-aqua groups and thus reduce or even suppress the activity of the catalyst. ${ }^{12}$ Moreover, this anchoring approach avoids the use of phosphonate or carboxylate moieties that have a limited stability in water in the presence of a supporting electrolyte under irradiation. ${ }^{13}$ In order to anchor our catalyst on MWCNTs, we prepared pyridyl type of ligands functionalized with the pyrenyl group as shown in Scheme 1, so that they can be anchored on MWCNTs via $\pi$-stacking interactions without significantly modifying the intrinsic electronic and geometrical properties of the parent complex. ${ }^{14}$ We synthesized ligand $\mathrm{L}^{1}$ that contains an amide group as previously described, ${ }^{15}$ and a new ligand $\mathrm{L}^{2}$ that contains a direct $\mathrm{C}-\mathrm{C}$ bond between the pyridyl group and the pyrene moiety, see Supporting Information (SI) for details. The latter strategy avoids the use of easily oxidizing methylene groups, which is fundamental for the long-term performance of any molecular water oxidation catalysts. ${ }^{16}$

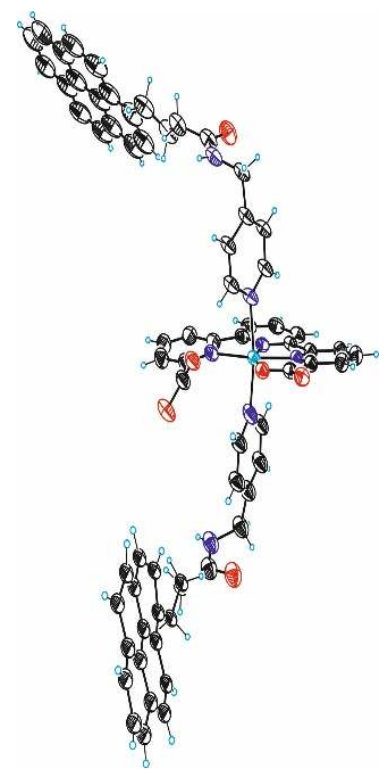

Figure 1. ORTEP plot of the catalyst precursor $\left\{\mathrm{Ru}^{\prime \prime}(\mathrm{tda})\left(\mathrm{L}^{1}\right)_{2}\right\}, \mathbf{1 b}$, (ellipsoids drawn at $50 \%$ probability). Color code: $\mathrm{Ru}$, cyan; $\mathrm{N}$, navy blue; $\mathrm{O}$, red; $\mathrm{C}$, black; $\mathrm{H}$, small cyan open circles.
The synthesis of complexes $\left\{R u(t d a)\left(L^{i}\right)_{2}\right\}(i=1,1 b ; i=2,1 c)$, is straightforward and similar to related complexes (see details of the synthesis in the $\mathrm{SI}) .^{10,15}$ A single crystal X-ray structure has been solved for $\mathbf{1 b}$ and its ORTEP plot is shown in Figure 1 . The latter complex shows a distorted octahedral coordination around the $\mathrm{Ru}(\mathrm{II})$ metal ion with the $\mathrm{tda}^{2-}$ ligand acting in a $k-\mathrm{N}^{3} \mathrm{O}$ fashion and leaving one of the carboxylate moieties uncoordinated. The axial positions are occupied by two pyridyl moieties from two $\mathrm{L}^{1}$ ligands. Overall, the structure of $\mathbf{1 b}$ shows a very similar first coordination sphere for the reported $\mathrm{Ru}$ as compared to $1 \mathrm{a}^{10} \mathrm{In}$ order to further electronically and structurally characterize these complexes, X-ray Absorption Spectroscopy (XAS) was carried out for powders of 1a, $\left\{\mathrm{Ru} \mathrm{u}^{\mathrm{II}}(\mathrm{tda})(\mathrm{py})_{2}\right\}\left(\mathrm{PF}_{6}\right)\left(\mathbf{1} \mathbf{a}\left(\mathrm{PF}_{6}\right)\right),\left\{\mathrm{Ru}^{\mathrm{IV}}(\mathrm{tda})(\mathrm{py})_{2}\right\}\left(\mathrm{PF}_{6}\right)_{2}\left(\mathbf{1} \mathbf{a}\left(\mathrm{PF}_{6}\right)_{2}\right)$, $1 \mathrm{~b}$ and $\mathrm{RuO}_{2}$ and the results are shown in Figure $2 \mathrm{~A}$ and the $\mathrm{SI}$. In all cases the half-edge energies obtained from $X$-ray Absorption Near Edge Structure (XANES) were consistent with the oxidation state assignment, and the metric parameters obtained by Extended X-ray Absorption Fine Structure (EXAFS) were very similar to those of related $X$-ray structures (Table S3). ${ }^{10}$

Glassy Carbon Disks $\left(\mathrm{GC}_{\mathrm{d}}, \mathrm{S}=0.07 \mathrm{~cm}^{2}\right)$ were used as working electrodes (WE) for all the electrochemical work described here except when larger surface areas were needed. In the latter case, Glassy Carbon Plates $\left(G_{p}, S=1 \mathrm{~cm}^{2}\right)$ were used. Further, a Pt disk and a $\mathrm{Hg} / \mathrm{HgSO}_{4}$ electrode were used as auxiliary and reference electrode respectively. All the potentials reported here are converted to NHE by adding $0.65 \mathrm{~V}$.

Conductive electrode materials were prepared by depositing a few $\mu \mathrm{L}$ of a suspension of MWCNTs on the surface of glassy carbon electrodes. The solvent was then allowed to evaporate and the new materials were labeled as "MWCNT@GC". They were then soaked in a solution of the catalyst precursor $\mathbf{1 b}$ or $1 \mathrm{c}$ affording the hybrid anode materials "\{Ru"(tda) $\left.\left(L^{i}\right)_{2}\right\} @ M W C N T @ G C "(i=1,2 \mathbf{b} ; i=2, \quad 2 \mathbf{c})$, that contained the catalyst precursor attached to the MWCNTs and were characterized by electrochemical techniques and XAS. 
"This is the peer reviewed version of the following article: A Million Turnover Molecular Anode for

Catalytic Water Oxidation, which has been published in final form at

http://onlinelibrary.wiley.com/doi/10.1002/anie.201609167/abstract

This article may be used for non-commercial purposes in accordance with Wiley Terms and Conditions for SelfArchiving."
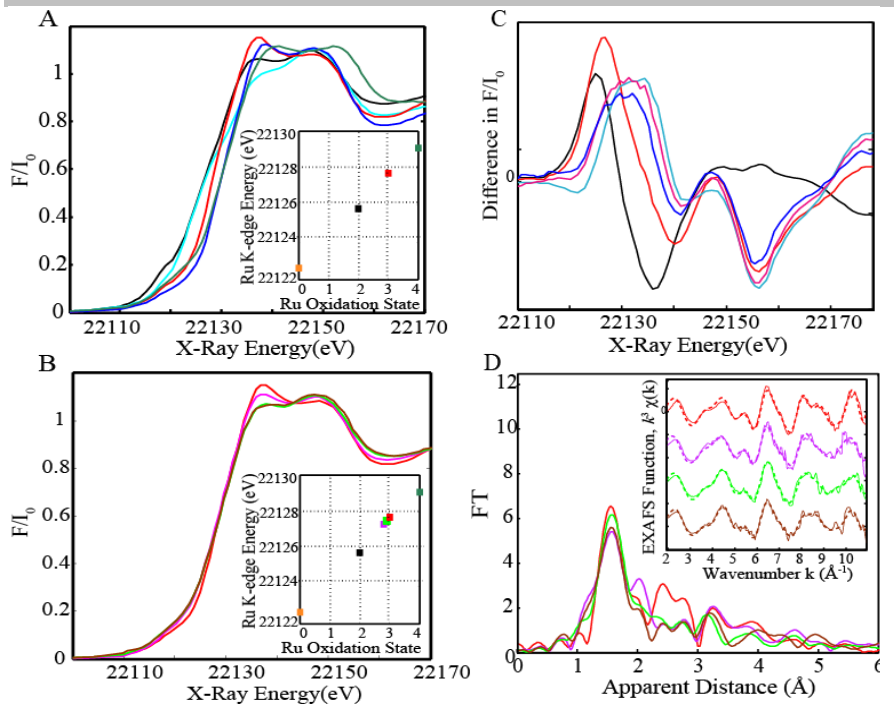

Figure 2. A, Normalized Ru K-edge XANES for 1a (black), 1b (cyan), $\mathbf{1 a}^{+}$(red) $1 \mathrm{a}^{2+}$ (blue) and $\mathrm{RuO}_{2}$ (dark green). Inset: Plot of half k-edge energy vs. oxidation state for $\mathrm{Ru}^{0}$ metal (orange), $1 \mathrm{a}$ and $\mathbf{1 b}$ (black), $\mathrm{aa}^{+}$(red) and $\mathrm{RuO}_{2}$ (dark green). B, Normalized Ru K-edge XANES for $\mathbf{1} \mathbf{a}^{+}$(red), $\mathbf{2} \mathbf{b}^{0}$ (magenta), 2b' (light green) and 2b" (brown). Inset: Plot of half k-edge energy vs oxidation state (same color code as in A) $\mathbf{2 b}^{\mathbf{0}}$ (magenta), $\mathbf{2 b}$ ' and $\mathbf{2 b}$ " (light green). C, Difference spectra for: $\mathbf{1 b}-1 \mathbf{a}^{+}$(black), $\mathbf{1 b}-\mathrm{RuO}_{2}$ (red), $\mathbf{1 a}^{+}-\mathrm{RuO}_{2}$ (cyan), $\mathbf{2 b}-\mathrm{RuO}_{2}$ (magenta) and $\mathbf{2} \mathbf{b}$ "- $\mathrm{RuO}_{2}$ (blue). D, Fourier transforms of $\mathrm{k}^{3}$ weighted Ru EXAFS for the Ru(III) complexes, $1 \mathbf{a}^{+}$(red) and $\mathbf{2 b}^{+}:\left(\mathbf{2} \mathbf{b}^{\mathbf{0}}-\mathbf{2 0} \%\right.$ 1b) magenta, (2b'-10\% 1b) (light green) and (2b"'-10\% 1b) brown. D. Back Fourier transformed experimental (solid lines) and fitted (dashed lines) $k^{3} x(k)$. Experimental spectra were calculated for $\mathrm{k}$ values of $1.941-10.9 \AA^{-1}$.

The amount of molecular complex deposited on the surface of the electrode turned out to be of $\Gamma_{\mathbf{2} b}=6.35 \mathrm{nmol} / \mathrm{cm}^{2}$ for $\mathbf{2 b}$ and $\Gamma_{2 c}=0.20 \mathrm{nmol} / \mathrm{cm}^{2}$ for $\mathbf{2 c}$. Further, XAS was carried out for $\mathbf{2 b}$ anchored on $\mathrm{GC}_{\mathrm{p}}$ in order to additionally characterize the nature of these hybrid materials. Unfortunately, the lower catalyst loading obtained for $\mathbf{2 c}$, even supported in the $\mathrm{GG}_{\mathrm{p}}$ electrode, prevented its XAS analysis. For $\mathbf{2 b}$ it was found that the nature of the molecular species attached to the surface of the MWCNTs was identical to those of the precursor complexes, except that atmospheric oxygen had oxidized the initial $\mathrm{Ru}(\mathrm{II})$ complex to $\mathrm{Ru}(\mathrm{III})$ by $80 \%$, as revealed by XANES and EXAFS (Figure $2 \mathrm{~B}$, Table S2). Additional evidence for this oxidation phenomenon was obtained by measuring the Open Circuit Potential (OCP) as a function of time for a sample of $\mathbf{2} \mathbf{b}$ in an open atmosphere (see Figure S30). We labelled this partially oxidized material as $\mathbf{2 b}^{0}$, and showed that its $\mathrm{Ru} k$-edge at half peak neatly correlates with oxidation state 2.8 and thus indicates that the sample $\mathbf{2} \mathbf{b}^{0}$ contains $80 \% \mathbf{2 b}^{+}$and $20 \% \mathbf{2 b}$ (Figure $2 \mathrm{~B}$, magenta). In addition, the simulated EXAFS experiments for $\mathbf{2 b}^{+}\left(\mathbf{2} \mathbf{b}^{0}-20 \%\right.$ 1b) also gives very good fits and thus further supports this point (see Figure 2D, Figure S33, Table S4 and Table S5 (fit 4)). The EXAFS simulations were carried out assuming a coordination number of $6(5 \mathrm{~N}, 10)$ for $\mathrm{Ru}(\mathrm{II})$ and assuming the typical pseudo-octahedral geometry expected for a $\mathrm{Ru}(\mathrm{II}) \mathrm{d}^{6}$ ion. On the other hand, for $\mathrm{Ru}(\mathrm{III})$ a coordination number of " 6.5 " was assumed $(5 \mathrm{~N}, 10,0.50)$, with a distorted octahedral coordination containing an additional oxygen contact (Ru-O distance of $2.4 \AA$ ), in a similar manner as found in the X-ray structure of $\mathbf{1 a}^{+}$(Figure S32, Table S4, fit 12). ${ }^{10}$ The data fit obtained for $\mathbf{1 a}^{+}$is very similar to that obtained for $\mathbf{2} \mathbf{b}^{+}$reflecting their structural similarities.

To generate the active catalyst at the surface of the electrode material, a potential of $1.25 \mathrm{~V}$ was applied for $500 \mathrm{~s}$ under stirring at $\mathrm{pH} 12$ to $\mathbf{2 b}$ or $\mathbf{2 c}$. This process oxidizes the initial $\mathrm{Ru}$ (II) complex to its oxidation state IV, where the coordination of a hydroxide anion occurs readily, ${ }^{10}$ as indicated in the equations 1 and 2 for $\mathbf{2 b}$.

Once generated, the active hybrid materials were removed from the $\mathrm{pH} 12$ solution, rinsed with water and introduced in another solution at $\mathrm{pH} 7$. Under these conditions, a mixture of $\mathbf{2 b}^{2+}$ and $\mathbf{3 b}$ is generated with an approximate ratio of 5:1 that remains in equilibrium, as deduced from cyclic voltammetry (CV) experiments at $\mathrm{pH} 7$ (See Figure 3 left).

Figure 3 shows that for the precursor material, waves for the III/II and IV/III couples are observed at $0.55 \mathrm{~V}$ and $1.10 \mathrm{~V}$ respectively, together with a large current density that appears at 1.3-1.4 V associated with the oxidation of the MWNCTs. On the other hand, on the $\mathrm{CV}$ of the $\mathbf{2 b}^{2+}: \mathbf{3 b}$ mixture, additional small waves appear in the 0.6-0.9 $\mathrm{V}$ potential range associated with the electroactivity of the anchored $\left\{\operatorname{Ru}^{\mathrm{IV}}(\mathrm{O})(\mathrm{tda})\left(\mathrm{L}^{1}\right)_{2}\right\}$ catalyst, $\mathbf{3 b}$, as we have earlier described for its homologue $\left\{\mathrm{Ru}^{\mathrm{IV}}(\mathrm{O})(\mathrm{tda})(\mathrm{py})_{2}\right\}$ in homogeneous phase. ${ }^{10}$
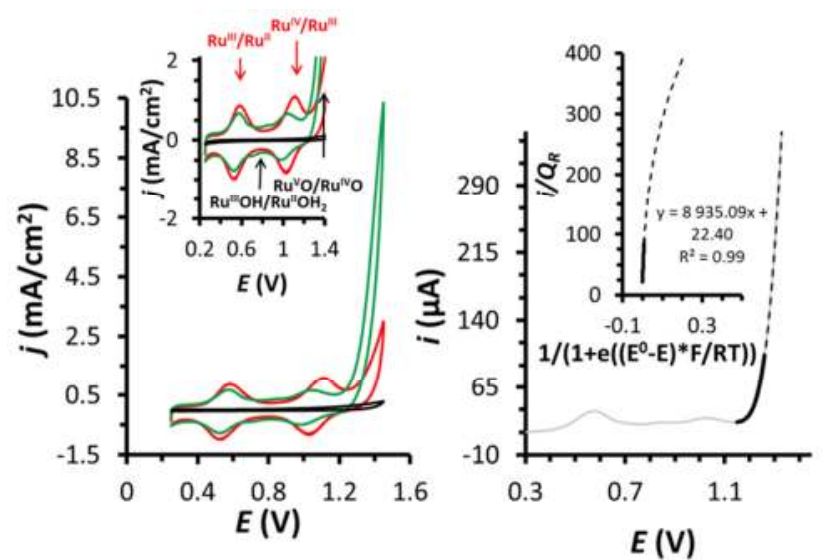

Figure 3. Left, red line, $\mathrm{CV}$ for $\mathbf{2} \mathbf{b}$ at in $\mathrm{pH} 7$ solution at a scan rate of 100 $\mathrm{mV} / \mathrm{s}$ from 0.25 to $1.45 \mathrm{~V}$, with a surface coverage of $\Gamma_{2 \mathrm{~b}}=6.35 \mathrm{nmol} / \mathrm{cm}^{2}$ using $\mathrm{GC}_{\mathrm{d}}$ as WE. Green line, CV of a mixture of $2 \mathrm{~b}^{2+}: \mathbf{3 b}\left(\Gamma_{2 b^{2+}}=2.66\right.$ $\mathrm{nmol} / \mathrm{cm} 2$ and $\Gamma_{3 b}=0.55 \mathrm{nmol} / \mathrm{cm}^{2}$ ) under the same conditions. In black a 
"This is the peer reviewed version of the following article: A Million Turnover Molecular Anode for Catalytic Water Oxidation, which has been published in final form at http://onlinelibrary.wiley.com/doi/10.1002/anie.201609167/abstract This article may be used for non-commercial purposes in accordance with Wiley Terms and Conditions for Self-
Archiving."

\begin{abstract}
blank for MWCNT@GC $\mathrm{C}_{\mathrm{d}}$. Inset, enlargement of the 0.2-1.4 V potential zone Right, linear sweep voltammetry at $\mathrm{pH} 7$ for the $2 \mathrm{~b}^{2+}: 3 \mathrm{~b}$ mixture (grey solid line). Inset, plot of $i / Q_{R}$ vs. [1/(1+e $\left.\left.\left(\left(E^{0}-E\right)^{\star} F / R T\right)\right)\right]$. The black dashed line in both cases represents the experimental data used for the FOWA analysis, and the black solid line shows the experimental data used for the extraction of TOF $_{\max }=8935 \mathrm{~s}^{-1}$ for $\mathbf{3 b}$.
\end{abstract}

Finally, a very large electrocatalytic current due to the oxidation of water to dioxygen associated with the $\mathrm{Ru}(\mathrm{V}) / \mathrm{Ru}(\mathrm{IV})$ couple occurs at 1.2-1.3 V, manifesting the high activity of this catalytic hybrid material. Interestingly, current densities above $10 \mathrm{~mA} / \mathrm{cm}^{2}$ are achieved here that are assumed to be critical for a potential construction of a water splitting device. ${ }^{17}$

We quantified the performance of this new solid state molecularanode for water oxidation, comparing its performances with its “\{Ru"(tda) $\left.\left(\mathrm{L}^{1}\right)_{2}\right\} @ M W C N T @ G C^{\prime}-2 \mathrm{e}^{-} \rightarrow$

2b

$$
\text { “\{Ru } \left.\left.\text { IV }^{\mathrm{I}} \mathrm{tda}\right)\left(\mathrm{L}^{1}\right)_{2}\right\}^{2+} @ M W C N T @ G C^{\prime \prime}
$$

$2 \mathbf{b}^{2+}$

“\{Rulv(tda) $\left.\left(\mathrm{L}^{1}\right)_{2}\right\}^{2+} @ M W C N T @ G C^{\prime \prime}+\mathrm{OH}^{-} \rightleftharpoons$

$2 b^{2+}$

“\{Rulv $\left.(O)(t d a)\left(L^{1}\right)\right\} @ M W C N T @ G C^{\prime}+H^{+}(2)$

3b

homogeneous homologue by carrying out a Foot of the Wave Analysis (FOWA) ${ }^{18}$ also at pH 7 (see Figure 3). A TOF $_{\max }=8935$ $\mathrm{s}^{-1}$ was obtained from the fitted data similar to that obtained for $\left\{\mathrm{Ru}^{\mathrm{IV}}(\mathrm{O})(\mathrm{tda})(\mathrm{py})_{2}\right\}^{10}{ }^{10}$ This is extremely important because it clearly shows that the activity of the catalyst anchored on a solid support, under translationally restricted mobility conditions, is maintained. It thus allows transferring the information obtained in homogeneous phase to the desired solid-state anode material, thanks to the WNA nature of the O-O bond formation step that occurs both in homogeneous phase and anchored. This is in sharp contrast with the related complex $\left\{\mathrm{Ru}^{\mathrm{IV}}(\mathrm{O})(\mathrm{bda})(4-\mathrm{Me}-\right.$ py $\left.)_{2}\right\} \quad\left(\right.$ bda $^{2-}$ is 6,6'-dicarboxylate-2,2'-bypyridine), that mechanistically operates via a bimolecular I2M mechanism. ${ }^{19}$ The latter, once anchored needs to change its mechanism to a higher energy pathway that significantly decrease the TOF $\max$ values and leads to degradation.

The activity of “ $\left\{\mathrm{Ru}^{\mathrm{IV}}(\mathrm{O})(\mathrm{tda})\left(\mathrm{L}^{2}\right)_{2}\right\} @ M W C N T @ G C$ ”, 3c, at pH 7 was also evaluated in a similar manner as that of $\mathbf{3 b}$, giving a $\mathrm{TOF}_{\max }=8076 \mathrm{~s}^{-1}$. This is very similar to that obtained for $\mathbf{3 b}$ (see Figure S24), further supporting the suitability of the chosen heterogenization strategy. The long-term stability of these new solid-state hybrid molecular anodes were evaluated at $\mathrm{pH} 7$ based on repetitive $\mathrm{CV}$, bulk electrolysis and XAS, shown in
Figures 2 and 4 . The upper part of Figure 4 displays 1000 repetitive CV scans carried out at $100 \mathrm{mV} / \mathrm{s}$ for the anodes containing mixtures of $2 \mathbf{b}^{2+}: \mathbf{3 b}$ and $2 \mathbf{c}^{2+}: \mathbf{3 c}$, between 0.25 and $1.45 \mathrm{~V}$. For the case of $2 \mathbf{b}^{2+}: \mathbf{3 b}$ (Figure 4 , top left), as the repetitive cycles proceed, both the intensity of the electrocatalytic current and the intensity of the waves due to the catalyst precursor progressively decrease, until no electroactivity is observed. Thus as the catalytic reaction proceeds, the catalyst and catalyst precursor progressively disappear from the surface of the electrode, most likely due to the oxidation of the linker. In sharp contrast for the case of $2 c^{2+}: 3 c$, the intensity of the electrocatalytic current decreases by approx. $65 \%$ of its initial value but the electroactivity of the precursor catalysts, $2 \mathbf{c}^{2+}$, remains intact as shown in Figure 4, top right. The change in the intensity of the electrocatalytic current at $1.45 \mathrm{~V}$ is mainly attributed to a shift of the equilibrated species between precursor $2 \mathrm{c}^{2+}$, and the active catalytic species $3 \mathrm{c}$ that occurs during long-term catalysis (see figure S25 for an inset of the molecular peaks). Also, a small decrease of the intensity can be attributed to the partial detachment of the MWCNT due most likely to a mechanical friction effect.

A similar trend is observed when bulk electrolysis experiments using $\mathrm{GC}_{\mathrm{d}}$ electrodes are carried out at $\mathrm{pH} 7$ with an applied potential of $1.45 \mathrm{~V}$ as can be seen in Figure 4, bottom. For the system $2 \mathbf{b}^{2+}: \mathbf{3 b}$ (red line), the initial current density reaches a value of $2 \mathrm{~mA} / \mathrm{cm}^{2}$, but as time elapses the current density progressively decreases to less than $0.25 \mathrm{~mA} / \mathrm{cm}^{2}$ after $2.5 \mathrm{~h}$. On the other hand, for the $2 \mathrm{c}^{2+}: 3 \mathrm{c}$ system (blue line) the initial current density is $1.5 \mathrm{~mA} / \mathrm{cm}^{2}$, and it decreases to $0.7 \mathrm{~mA} / \mathrm{cm}^{2}$ at about 40 minutes and then remains constant. While the hybrid anode $2 c^{2+}: 3 c$ is extremely stable generating roughly 0.18 million TNs without apparent deactivation, $\mathbf{2 b}^{2+}: \mathbf{3 b}$ slowly deactivates but still giving a remarkable final TNs of 0.67 million. TNs in the range of 1.2 million can be obtained for $2 c^{2+}: 3 c$ under similar conditions but by running the experiment for longer periods of time (12h; see figure S27). The strikingly different long-term performances of these two anode materials are associated with the different oxidative stability of their linking moieties as discussed above for the repetitive CV experiments.

These results manifest again the importance of ligand design for long lasting anodes for water splitting applications that if properly designed can parallel the performance of related oxide based electroanodes. ${ }^{20}$ Finally, a bulk electrolysis experiment was performed in a $\mathrm{GC}_{\mathrm{p}}$ for $\mathbf{2} \mathbf{b}^{2+}: \mathbf{3 b}$ under similar conditions, and the amount of $\mathrm{O}_{2}$ generated was measured via a Clark electrode on the gas phase giving a Faradaic efficiencies above $90 \%$, showing once more the ruggedness of the present system (Figure S28). The remaining current is basically used for the oxidation of the graphite electrode. 
"This is the peer reviewed version of the following article: A Million Turnover Molecular Anode for Catalytic Water Oxidation, which has been published in final form at http://onlinelibrary.wiley.com/doi/10.1002/anie.201609167/abstract

This article may be used for non-commercial purposes in accordance with Wiley Terms and Conditions for SelfArchiving."

The structure of the hybrid material $2 \mathbf{b}^{2+}: \mathbf{3 b}$ was also analyzed by XAS, using glassy carbon plates $\mathrm{GC}_{\mathrm{p}}$ and the results are reported in Figure 2, S32, S33 and Tables S3 and S5. Two samples of the hybrid material $2 \mathbf{b}^{2+}: \mathbf{3 b}\left(\Gamma_{2 b^{2+}}=0.57 \pm 0.16\right.$ $\mathrm{nmol} / \mathrm{cm}^{2}$ and $\Gamma_{3 b}=0.64 \pm 0.24 \mathrm{nmol} / \mathrm{cm}^{2} ; \Gamma_{2 b^{2+}}: \Gamma_{3 b}=0.89 \pm 0.20$ $\mathrm{nmol} / \mathrm{cm}^{2}$ ) were exposed to a bulk electrolysis experiment at $\mathrm{pH}$ 7 , with an applied potential of $1.45 \mathrm{~V}$ for $1000 \mathrm{~s}$ for the first sample and for $1 \mathrm{~h}$ for the second one.
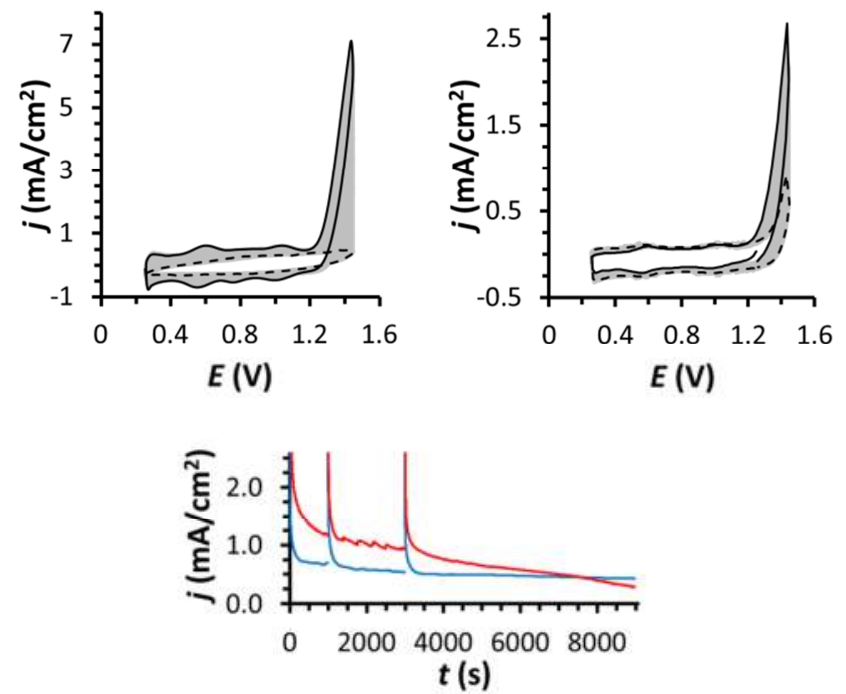

Figure 4. Top, 1000 repetitive $\mathrm{CV}$ scans at $\mathrm{pH} 7$ at a scan rate of $100 \mathrm{mV} / \mathrm{s}$ from 0.25 to $1.45 \mathrm{~V}$ for $\mathbf{2 b}^{2+}: \mathbf{3 b}$ (left, $\Gamma_{\mathbf{2} \boldsymbol{b}^{2+}}=2.07 \mathrm{nmol} / \mathrm{cm}^{2}$ and $\Gamma_{\mathbf{3}}=0.36$ $\mathrm{nmol} / \mathrm{cm}^{2}$ ) and $2 \mathrm{c}^{2+}: 3 \mathrm{c}$ (right, $\Gamma_{2 c^{2+}}=0.13 \mathrm{nmol} / \mathrm{cm}^{2}$ and $\Gamma_{3 c}=0.03 \mathrm{nmol} / \mathrm{cm}^{2}$ ) at $\mathrm{GC}_{\mathrm{d}}$. Black solid line is the first cycle, black dashed line is the $1000^{\text {th }}$ cycle. In grey are $2^{\text {nd }}-999^{\text {th }}$ cycles. Bottom, bulk electrolysis of $2 \mathbf{b}^{2+}: 3 \mathbf{b}$ (red, $\Gamma_{2 b^{2+}}=2.10$ $\mathrm{nmol} / \mathrm{cm}^{2}$ and $\Gamma_{3 b}=0.40 \mathrm{nmol} / \mathrm{cm}^{2}$ ) and $2 \mathrm{c}^{2+}: 3 \mathrm{c}$ (blue, $\Gamma_{2 c^{2+}}=0.11 \mathrm{nmol} / \mathrm{cm}^{2}$ and $\Gamma_{3 c}=0.03 \mathrm{nmol} / \mathrm{cm}^{2}$ ) in a phosphate buffered solution at $\mathrm{pH} 7$ at $E_{\text {app }}=$ $1.45 \mathrm{~V}$ under stirring using $\mathrm{GC}_{\mathrm{d}}$ as WE. The experiments were stopped at $1000 \mathrm{~s}$ and $3000 \mathrm{~s}$ and then subsequently reinitialized. See Figure S29 for an analogous experiment on bare MWCNT@GC

Subsequently a CV was carried out with a final potential of $0.2 \mathrm{~V}$ that generated the catalyst precursor and the active catalyst at oxidation state II, that are labeled as $\mathbf{2}$ b' and $\mathbf{2 b}$ " for the samples exposed to $1000 \mathrm{~s}$ and $1 \mathrm{~h}$ electrolysis, respectively, and left in open air for a week. As was also the case for $\mathbf{2 b}^{\mathbf{0}}$, XANES spectra show half peak $k$-edge energies that indicate that initial $\mathrm{Ru}(\mathrm{II})$ complex is oxidized to $\mathrm{Ru}(\mathrm{III})$ by $90 \%$ in both cases (see Table S2 and top inset in Figure $2 \mathrm{~B}$ ). In addition, the EXAFS (see Figures 2D, S32, Table S3 and Table S5 (fits 4, 8 and 12)) point out that the samples before catalysis $2 \mathbf{2 b}^{0}$ and after $1000 \mathrm{~s}$ and $1 \mathrm{~h}$ catalysis $\mathbf{2} \mathbf{b}$ ' and $\mathbf{2 b}$ " respectively, are practically identical to $\mathbf{1 a}^{+}$, after subtraction of their $\mathrm{Ru}(\mathrm{II})$ contribution, and thus confirms the presence of $\mathbf{2} \mathbf{b}^{+}$. This is a very important result since it shows that the nature of the catalyst remains intact after catalysis. In addition, XAS spectroscopy unambiguously shows the absence of any traces of $\mathrm{RuO}_{2}$ after $1 \mathrm{~h}$ catalysis. This can be monitored by the specific peak at $22156 \mathrm{eV}$, nicely visualized through the difference spectra in Figure $2 \mathrm{C}$, that is highly characteristic of $\mathrm{RuO}_{2}$ as well as by the absence of $\mathrm{RuO}_{2}$ in the EXAFS spectral features shown in Figure 2D and S33. This is again very significant since it clearly demonstrates the molecular nature of the catalysis in heterogeneous phase, in sharp contrast with many instances where the original molecular catalyst is transformed to the corresponding metal oxide that ends up being the real active catalyst. ${ }^{6}$

In conclusion, the present work reports a million turnover molecular electroanode that consists of a molecular Ru catalyst anchored on the surface of MWCNTs via a pyrenyl functionality. The extraordinary unprecedented stability of the molecular catalyst is a result of a bottom up approach that includes a thorough mechanistic understanding of the water oxidation catalyst steps involved in water nucleophilic attack events. XAS spectroscopy has been shown to be a very valuable tool in the solid state to monitor the long-term stability and molecular nature of the anchored water oxidation catalysts.

\section{Acknowledgements}

A.L., X.S. and J.G-A thank MINECO (CTQ-2013-49075-R, SEV2013-0319; CTQ-2014-52974-REDC and CTQ2015-64261-R). J.C. and R.M respectively thank UAB, "Euroregió Pirineus Mediterrània" and "La Caixa" for PhD grants. D.M. acknowledges support from the US DOE, Contract No. DEAC02-06-CH11357. J.G-A. thanks Serra Húnter Program.

Keywords: water oxidation catalysis, electrocatalysis, water splitting, redox properties, transition metal complexes,

1 N. S. Lewis, Science 2016, 351,19201-19209.

2 L. Alibabaei, B. D. Sherman, M. R. Norris, M. K. Brennaman, T. J. Meyer, Proc. Natl. Acad. Sci. USA 2015, 112, 5899-5902.

3 X. Elias, Q. Liu, C. Gimbert-Suriñach, R. Matheu, P. Mantilla-Perez, A. Martinez-Otero, X. Sala, J. Martorell, A. Llobet, ACS Catal. 2016, 33103316.

4 J. H. Kim, Y. Jo, J. H. Kim, J. W. Jang, H. J. Kang, Y. H. Lee, D. S. Kim, Y. Jun, J. S. Lee, ACS Nano 2015, 9, 11820-11829.

5 G. Pastori, K. Wahab, A. Bucci, G. Bellachioma, C. Zuccaccia, J. Llorca, H. Idriss, A. Macchioni, Chem. Eur. J. 2016, DOI: 10.1002/chem.201602008 
"This is the peer reviewed version of the following article: A Million Turnover Molecular Anode for

Catalytic Water Oxidation, which has been published in final form at

http://onlinelibrary.wiley.com/doi/10.1002/anie.201609167/abstract

This article may be used for non-commercial purposes in accordance with Wiley Terms and Conditions for SelfArchiving."

6 R. Matheu, L. Francàs, P. Chernev, M. Z. Ertem, V. Batista, M. Haumann, X. Sala, A. Llobet, ACS Catal. 2015, 3422-3429.

7 X. Sala, S. Maji, R. Bofill, J. Garcia-Anton, L. Escriche, A. Llobet, Acc. Chem. Res. 2014, 47, 504-516.

8 J. J. Concepcion, J. W. Jurss, J. L. Templeton, T. J. Meyer, J. Am. Chem. Soc 2008, 130, 16462-16463

9 N. Karousis, N.Tagmatarchis. D. Tasis Chem. Rev. 2010, 110, 5366-5397.

10 R. Matheu, M. Z. Ertem, J. Benet-Buchholz, E. Coronado, V. S. Batista, X. Sala, A. Llobet, J. Am. Chem. Soc. 2015, 137, 10786-10795.

11 C. C. L. McCrory, S. Jung, I. M. Ferrer, S. M. Chatman, J. C. Peters, T. F. Jaramillo, J. Am. Chem. Soc. 2015, 137, 4347-4357.

12 L. Francàs, C. Richmond, P. Garrido-Barros, N. Planas, S. Roeser, J. Benet-Buchholz, L. Escriche, X. Sala, A. Llobet, Chem. Eur. J. 2016, 22, 5261-5268.
13 J. T. Hyde, K. Hanson, A. K. Vannucci, A. M. Lapides, L. Alibabaei, M. R. Norris, T. J. Meyer, D. P. Harrison, ACS Appl. Mater. Interfaces 2015, 7 , 9554-9562.

14 A. Maurin, M. Robert, J. Am. Chem. Soc. 2016, 138, 2492-2495.

$15 \mathrm{~F}$. Li, B. Zhang, X. Li, Y. Jiang, L. Chen, Y. Li, L. Sun, Angew. Chem. Int Ed. 2011, 50, 12276-12279.

16 D. Hong, S. Mandal, Y. Yamada, Y.-M. Lee, W. Nam, A. Llobet, S. Fukuzumi, Inorg. Chem. 2013, 52, 9522-9531.

17 M. G. Walter, E. L. Warren, J. R. McKone, S. W. Boettcher, Q. Mi, E. A Santori, N. S. Lewis, Chem. Rev. 2010, 110, 6446-6473.

18 C. Costentin, S. Drouet, M. Robert, J.-M. Savéant, J. Am. Chem. Soc. 2012, 134, 11235-11242.

19 L. Duan, F. Bozoglian, S. Mandal, B. Stewart, T. Privalov, A. Llobet, L. Sun, Nat. Chem. 2012, 4, 418-423. 
"This is the peer reviewed version of the following article: A Million Turnover Molecular Anode for

Catalytic Water Oxidation, which has been published in final form at

http://onlinelibrary.wiley.com/doi/10.1002/anie.201609167/abstract

This article may be used for non-commercial purposes in accordance with Wiley Terms and Conditions for SelfArchiving."

\section{COMMUNICATION}

Oxidatively stable molecular water oxidation anodes reaching more than a million turnover numbers with no molecular degradation

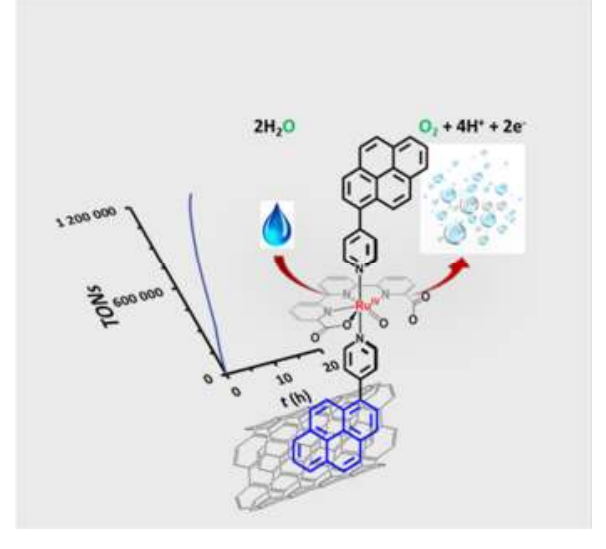

Jordi Creus, Roc Matheu, Itziar Peñafiel, Dooshaye Moonshiram, Pascal Blondeau, Jordi BenetBuchholz, Jordi García-Antón, Xavier Sala, ${ }^{*}$ Cyril Godard, * Antoni Llobet *

Page No. - Page No. 